Atmos. Chem. Phys., 18, 14243-14251, 2018

https://doi.org/10.5194/acp-18-14243-2018

(C) Author(s) 2018. This work is distributed under

the Creative Commons Attribution 4.0 License.

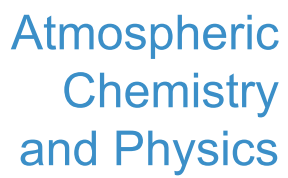

(c) (†)

\title{
Can semi-volatile organic aerosols lead to fewer cloud particles?
}

\author{
Chloe Y. Gao ${ }^{1,2}$, Susanne E. Bauer ${ }^{2,3}$, and Kostas Tsigaridis ${ }^{3,2}$ \\ ${ }^{1}$ Department of Earth and Environmental Sciences, Columbia University, New York, NY 10027, USA \\ ${ }^{2}$ NASA Goddard Institute for Space Studies, New York, NY 10025, USA \\ ${ }^{3}$ Center for Climate Systems Research, Columbia University, New York, NY 10025, USA
}

Correspondence: Kostas Tsigaridis (kostas.tsigaridis@ columbia.edu)

Received: 10 April 2018 - Discussion started: 24 April 2018

Revised: 13 September 2018 - Accepted: 20 September 2018 - Published: 8 October 2018

\begin{abstract}
The impact of condensing organic aerosols on activated cloud number concentration is examined in a new aerosol microphysics box model, MATRIX-VBS. The model includes the volatility basis set (VBS) framework coupled with the aerosol microphysical scheme MATRIX (Multiconfiguration Aerosol TRacker of mIXing state) that resolves aerosol mass and number concentrations and aerosol mixing state. By including the condensation of organic aerosols, the new model produces fewer activated particles compared to the original model, which treats organic aerosols as nonvolatile. Parameters such as aerosol chemical composition, mass and number concentrations, and particle sizes that affect activated cloud number concentration are thoroughly tested via a suite of Monte Carlo simulations. Results show that by considering semi-volatile organics in MATRIX-VBS, there is a lower activated particle number concentration, except in cases with low cloud updrafts, in clean environments at above-freezing temperatures, and in polluted environments at high temperatures $(310 \mathrm{~K})$ and extremely low-humidity conditions.
\end{abstract}

\section{Introduction}

Atmospheric aerosols influence climate mainly via two pathways: aerosol-radiation interactions (the aerosol direct effect; Charlson et al., 1992), which affect the Earth's radiative energy balance by absorbing and scattering terrestrial and solar radiation, and aerosol-cloud interactions (the aerosol indirect effect; Twomey, 1974; Albrecht, 1989), which affect cloud microphysics by activating and serving as seeds for cloud formation (Myhre et al., 2013; Seinfeld and Pandis, 2016). Aerosol activation as cloud condensation nu- clei $(\mathrm{CCN})$ is critical to the evolution and microphysics of clouds (Reutter et al., 2009). However, the relationship between aerosol mixing state and cloud microphysical properties remains a large uncertainty in aerosol-cloud interactions (Ghan et al., 1998; McFiggans et al., 2006; Ervens et al., 2007; Gibson et al., 2007; Medina et al., 2007; Cubison et al., 2008; Anttila, 2010).

Climate models calculate cloud droplet number concentration (CDNC) using aerosol activation schemes, whose main governing parameters include aerosol number, size, hygroscopicity, updraft velocity, and critical supersaturation. Physically based aerosol activation schemes (e.g., Abdul-Razzak and Ghan, 2000; Fountoukis and Nenes, 2005; Ming et al., 2006; Shipway and Abel, 2010) are commonly used in global climate models for fast diagnostics of nucleation and to estimate the aerosol indirect effect in long-term climate simulations (Ghan et al., 2011). Several studies examined the relationship between the aforementioned parameters and how they interact to activate particles. Ghan et al. (1998) examined sea salt's influence on sulfate particle activation and introduced the competition effect. Since all CCN have to compete for available water vapor in order to activate, the competition limits the maximum supersaturation in in-cloud updrafts (Storelvmo et al., 2006). Ghan et al. (1998) concluded that activated number concentration increases with increasing sea salt when sulfate is low and updraft is strong, and it decreases when sulfate is high and updraft is weak because maximum supersaturation is reduced. Another study (Reutter et al., 2009) explored how much CDNC depends on updraft velocity, size distribution, and hygroscopicity. They found that size distribution played a greater role than particle hygroscopicity in CDNC and discovered different CCN acti- 
Table 1. Hygroscopicity $\kappa$ used for each organic aerosol volatility bin.

\begin{tabular}{lrrr}
\hline & $\begin{array}{r}\log _{10} C^{*} \\
\left(\mu \mathrm{g} \mathrm{m}^{-3}\right)\end{array}$ & $\begin{array}{r}\text { Soluble } \\
\text { fraction }(\%)\end{array}$ & $\kappa$ \\
\hline Sulfate & $/$ & 100 & 0.507 \\
\hline Black carbon & $/$ & 0 & $5 \times 10^{-7}$ \\
\hline Nonvolatile organic carbon & $/$ & 78 & 0.141 \\
\hline & -2 & 100 & 0.180 \\
& -1 & 87.5 & 0.158 \\
Semi-volatile organic carbon & 0 & 75 & 0.135 \\
& 2 & 62.5 & 0.113 \\
& 3 & 50 & 0.090 \\
& 4 & 25 & 0.068 \\
& 5 & 12.5 & 0.045 \\
& 6 & 0 & 0.000 \\
\hline Dust & $/$ & 13 & 0.14 \\
\hline Sea salt & $/$ & 100 & 1.335 \\
\hline
\end{tabular}

vation and cloud droplet formation regimes, which are determined by aerosol number concentration and updraft velocity.

Semi-volatile organic aerosols contribute significantly to the growth of particles to CCN sizes (Yu, 2011). More notably, as aerosol size increases, the range of organic volatilities involved in aerosol growth increases (Pierce et al., 2011; $\mathrm{Yu}, 2011)$. The inclusion of semi-volatile organics in models modifies CCN formation rates (Petters et al., 2006; Riipenen et al., 2011; Scott et al., 2015) as well as hygroscopicity (Petters and Kreidenweis, 2007), in addition to bulk aerosol mass, size distribution, and composition. By adding semivolatile organic partitioning to our existing microphysics model MATRIX (Multiconfiguration Aerosol TRacker of mIXing state; Bauer et al., 2008), which resolves aerosol mixing state, we were able to examine how semivolatile organics change bulk aerosol mass, size distribution, and composition. However, the effects of semi-volatile organic partitioning combined with aerosol mixing state on particle activation remain unexplored.

In our previous work, we demonstrated that including semi-volatile organics would lead to higher aerosol number concentration and smaller particles (Gao et al., 2017). As was the case for the original aerosol microphysics model MATRIX, our further-developed box model MATRIX-VBS (Gao et al., 2017) follows the same multimodal aerosol activation approach by Abdul-Razzak and Ghan (2000). The activation parameterization accounts for aerosol size distribution, composition, mixing state, and in-cloud updraft velocity. Curious about the change in activation with the newly present semi-volatile organics and the governing parameters influencing it, we investigated the difference in activated number concentration in two box model setups: MATRIX (Bauer et al., 2008) and MATRIX-VBS (Gao et al., 2017).

\section{Methods}

\subsection{Model description}

MATRIX-VBS (Gao et al., 2017) is an aerosol microphysics model that includes organic aerosol volatility in its calculations. It was developed by implementing VBS (volatility basis set; Donahue et al., 2006) in the aerosol microphysics model MATRIX (Bauer et al., 2008), which is a box model that is also used in the NASA GISS ModelE Earth system model (Bauer et al., 2008; Bauer and Menon, 2012; Schmidt et al., 2014). Since the publication of Gao et al. (2017), which included organic condensation on fine-mode aerosols, we further developed the model, which now allows semi-volatile organics in the system to condense on coarse-mode dust and sea salt as well. We have also included nitrate radicals as an oxidant for organics in addition to the hydroxyl radical that was used in the original VBS scheme, even though it is a very minor oxidation pathway in the model (rate constant for the oxidation by $\mathrm{NO}_{3} \cdot$ is $1 \times 10^{-13} \mathrm{~cm}^{3}$ molecules ${ }^{-1} \mathrm{~s}^{-1}$; Atkinson, 1997). As previously stated, we use the activation parameterization of Abdul-Razzak and Ghan (2000), which calculates the activated particle number concentration depending on chemically resolved number concentrations using Köhler theory. The hygroscopicity parameters $\kappa$ for each aerosol species presented in Table 1 were calculated from their solubility fraction. For organics, we assumed a linear increase in solubility with decreasing volatility (Jimenez et al., 2009). Since we use Pankow-type partitioning (Pankow, 1994), water is not considered in the partitioning process. In addition, we do not use different kappa-relative humidity $(\mathrm{RH})$ relationships per organic species, which was found to be important for biogenic secondary organic aerosol (SOA) (Rastak et al., 2017).

\subsection{Simulations}

A Monte Carlo analysis with a range of chemical and meteorological conditions (Table 2) was performed to pinpoint which processes affect organics and the mixed aerosol population in general the most. Since global models need to resolve a wide range of conditions, from very clean to very polluted, and for a wealth of meteorological conditions, we simulated 630 possible atmospheric scenarios on Earth across the whole parameter space, e.g., temperature, $\mathrm{RH}$, latitude, emissions levels, and updraft velocity, for $120 \mathrm{~h}$ (5 days) simulations with no deposition and dilution. Three types of environmental conditions were simulated: clean, moderate, and polluted, as defined by different levels of emissions that were determined using a probability distribution of the gridded emission fields in GISS ModelE for January present-day conditions. During this development phase, biogenic SOAs from terpene oxidation in MATRIX-VBS are treated as nonvolatile, while only the anthropogenic aerosols are treated as semi-volatile. 
Table 2. Parameters used in the Monte Carlo simulations.

\begin{tabular}{|c|c|c|}
\hline Parameter & & Range \\
\hline $\begin{array}{l}T(\mathrm{~K}) \\
\text { RH }(\%) \\
\text { Latitude } \\
\text { Updraft velocity }\left(\mathrm{m} \mathrm{s}^{-1}\right)\end{array}$ & & $\begin{array}{l}270,280,290,300,310 \\
0.1,20,40,60,80,100 \\
0,30^{\circ} \mathrm{N} / \mathrm{S}, 60^{\circ} \mathrm{N} / \mathrm{S}, 90^{\circ} \mathrm{N} / \mathrm{S} \\
0.5,1,2\end{array}$ \\
\hline Emissions of aerosols $\left(\mu \mathrm{g} \mathrm{m}^{-3} \mathrm{~s}^{-1}\right)$ & $\begin{array}{l}\text { Sulfate }\left(\mathrm{SO}_{2} \text { in molecules } \mathrm{cm}^{-3}\right) \\
\text { Primary organics } \\
\text { Nonvolatile biogenic organics from terpene source } \\
\text { Black carbon }\end{array}$ & $\begin{array}{l}10^{5}, 10^{6}, 5 \times 10^{6} \\
5 \times 10^{-6}, 5 \times 10^{-5}, 5 \times 10^{-4} \\
1 \times 10^{-8}, 5 \times 10^{-6}, 1 \times 10^{-5} \\
10^{-6}, 10^{-5}, 10^{-4}\end{array}$ \\
\hline Emissions of gases (molecules $\mathrm{cm}^{-3}$ ) & $\begin{array}{ll}\text { Volatile organic compounds (in sets) } & \text { Alkenes } \\
& \text { Paraffin } \\
& \text { Terpenes } \\
& \text { Isoprene }\end{array}$ & $\begin{array}{l}5 \times 10^{2}, 5 \times 10^{3}, 5 \times 10^{4} \\
5 \times 10^{3}, 10^{4}, 5 \times 10^{4} \\
10^{4}, 10^{5}, 10^{6} \\
10^{4}, 10^{5}, 50^{6} \\
10^{5}, 10^{6}, 10^{7}\end{array}$ \\
\hline
\end{tabular}
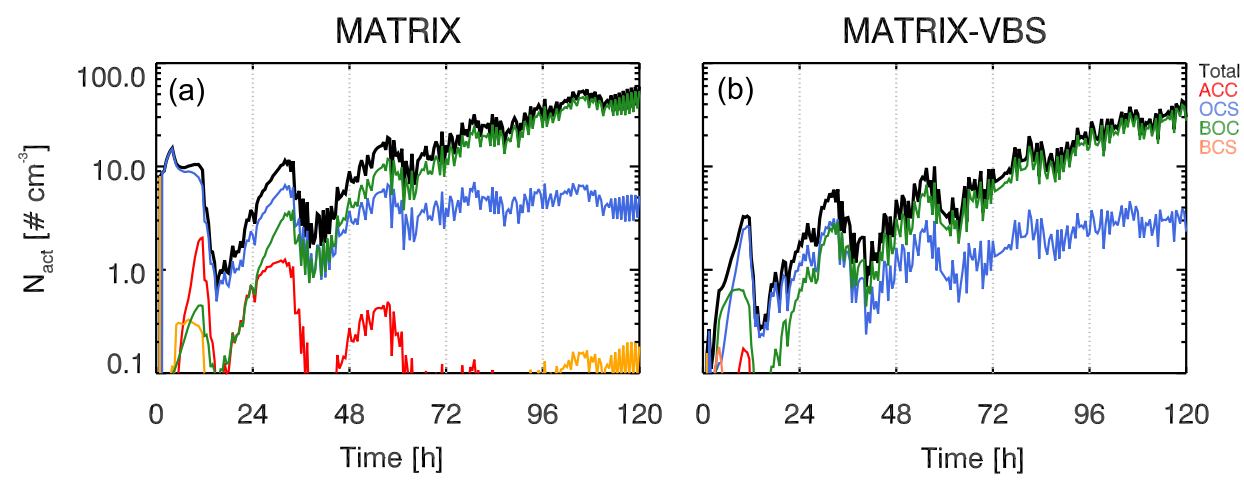

Figure 1. Activated number concentration of aerosol populations (see main text for details) for MATRIX (a) and MATRIX-VBS (b) for $290 \mathrm{~K}$ and $40 \% \mathrm{RH}$ at $30^{\circ} \mathrm{N}$ latitude with medium emission levels and $0.5 \mathrm{~m} \mathrm{~s}^{-1}$ updraft velocity.

\section{Results and discussion}

We found that activated number concentration is lower for most cases in the MATRIX-VBS model, which considers semi-volatile organic aerosols, compared to the MATRIX model. However, under low updrafts, in a clean environment at above-freezing temperatures, and in polluted environments at high temperatures $(310 \mathrm{~K})$ and extremely lowhumidity conditions $(0 \% \mathrm{RH})$ during aerosol formation, activated number concentration is higher in MATRIX-VBS than in MATRIX.

As an example, the activated number concentration for a case with temperature at $290 \mathrm{~K}, \mathrm{RH}$ at $40 \%$, medium emission levels, and an updraft of $0.5 \mathrm{~m} \mathrm{~s}^{-1}$ at $30^{\circ} \mathrm{N}$ latitude is shown in Fig. 1 for the two models. Mixing states of aerosols in MATRIX and MATRIX-VBS are represented as aerosol populations, which all contain $\mathrm{SO}_{4}, \mathrm{NO}_{3}, \mathrm{NH}_{4}$, and $\mathrm{H}_{2} \mathrm{O}$, in addition to the species that define the populations (Bauer et al., 2008, 2013). The four most dominant aerosol populations for the activated number concentration in MATRIX are $\mathrm{ACC}\left(\mathrm{SO}_{4}, \mathrm{NO}_{3}, \mathrm{NH}_{4}\right)$, OCS (organic carbon, $\mathrm{SO}_{4}$, $\mathrm{NO}_{3}, \mathrm{NH}_{4}$ ), BOC (black carbon, organic carbon, $\mathrm{SO}_{4}, \mathrm{NO}_{3}$, $\mathrm{NH}_{4}$ ), and $\mathrm{BCS}$ (black carbon, $\mathrm{SO}_{4}, \mathrm{NO}_{3}, \mathrm{NH}_{4}$ ). Only two dominant populations are calculated in MATRIX-VBS, OCS and BOC, as in Gao et al. (2017), since OCC evaporates and re-condenses on all particles, based on their calculated surface area and mass concentration. Since OCS and BOC have the largest surface area, they are calculated to have the strongest growth via organics condensation. Additionally, the competition among sulfate, organics, and black carbon determines the loss of ACC and the formation of BCS: OCC coagulates with ACC to form OCS, and this coagulation increases in MATRIX-VBS due to smaller OCC particles; therefore, there are fewer ACC particles left to coagulate with black carbon to form BCS. At the end of the 5-day simulation (Fig. 1), MATRIX-VBS has a total of approximately 30 activated particles $\mathrm{cm}^{-3}$, whereas MATRIX has approximately 60 activated particles $\mathrm{cm}^{-3}$ under the same conditions. 


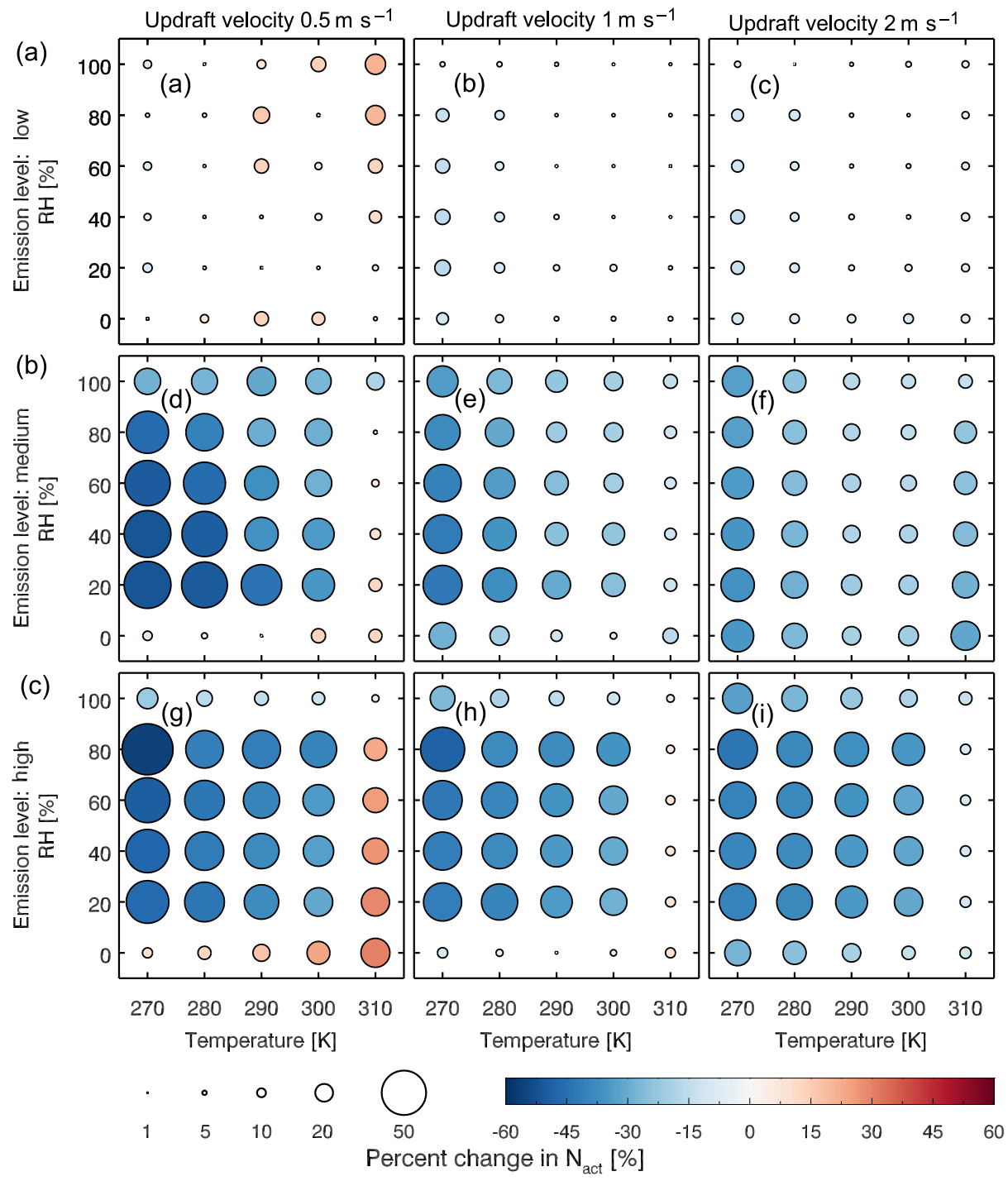

Figure 2. Fractional change of the average activated number concentration (size and color of the circles) over the last $24 \mathrm{~h}$ of a 5 -day simulation between the two models with low-level (a, b, c), medium-level (d, e, f), and high-level (g, $\mathbf{h}, \mathbf{i})$ emissions at updraft velocities of 0.5 (a, d, g), 1 (b, e, h), and $2(\mathbf{c}, \mathbf{f}, \mathbf{i}) \mathrm{m} \mathrm{s}^{-1}$.

Table 3. Minimum and maximum of fractional change in average activated number concentration over the last $24 \mathrm{~h}$ between the two models with low-, medium-, and high-level emissions at updraft velocities of $0.5,1$, and $2 \mathrm{~m} \mathrm{~s}^{-1}$.

\begin{tabular}{lrr|rr|rr}
\hline & \multicolumn{6}{c}{ Fractional change in activated number concentration } \\
\cline { 2 - 7 } Updraft velocity $\left(\mathrm{m} \mathrm{s}^{-1}\right)$ & 0.5 & 1 & \multicolumn{2}{|c|}{2} \\
\hline & Min & Max & Min & Max & Min & Max \\
\hline Low emission level & $-9 \%$ & $+21 \%$ & $-16 \%$ & $+2 \%$ & $-14 \%$ & $+5 \%$ \\
Medium emission level & $-51 \%$ & $+14 \%$ & $-42 \%$ & $-5 \%$ & $-36 \%$ & $-13 \%$ \\
High emission level & $-56 \%$ & $+31 \%$ & $-48 \%$ & $+9 \%$ & $-43 \%$ & $-9 \%$ \\
\hline
\end{tabular}

Figure 2 shows a more comprehensive look across all temperature and RH scenarios studied. The results show that for most scenarios, MATRIX-VBS has lower (blue circles) ac- tivated number concentration compared to MATRIX. However, some rare cases show the opposite behavior. These are for above-freezing temperatures in the low emission 


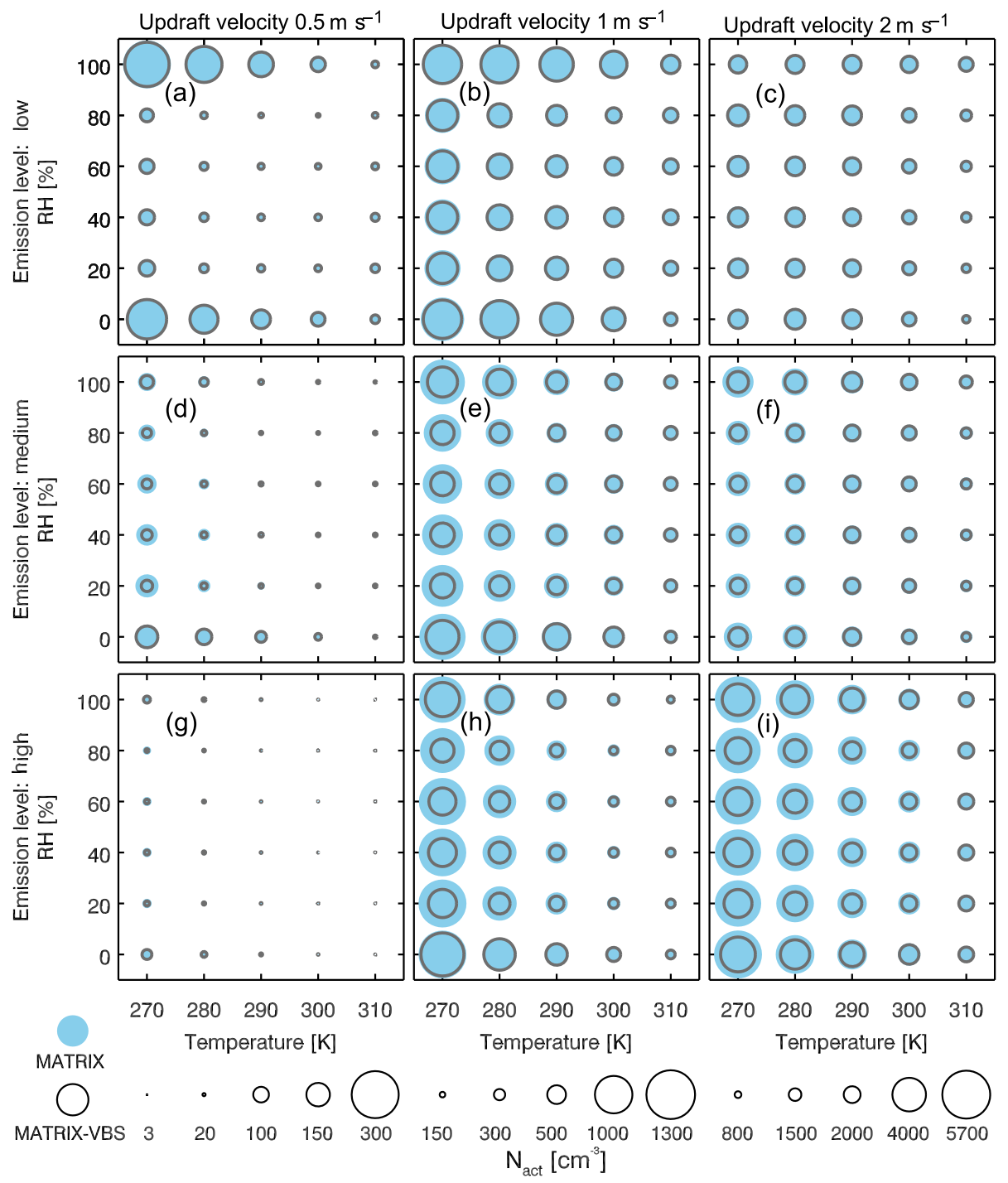

Figure 3. Average activated number concentration (circle size) during the last $24 \mathrm{~h}$ of a 5-day simulation in MATRIX and MATRIX-VBS with low $(\mathbf{a}, \mathbf{b}, \mathbf{c})$, medium $(\mathbf{d}, \mathbf{e}, \mathbf{f})$ and high $(\mathbf{g}, \mathbf{h}, \mathbf{i})$ emission levels at updraft velocities of $0.5(\mathbf{a}, \mathbf{d}, \mathbf{g}), 1(\mathbf{b}, \mathbf{e}, \mathbf{h})$, and $2(\mathbf{c}, \mathbf{f}, \mathbf{i}) \mathrm{m} \mathrm{s}^{-1}$. Note the difference in scales per column.

level under low-updraft (top left) scenarios, high temperature $(310 \mathrm{~K})$, and extremely low humidity $(0 \% \mathrm{RH})$ in the medium emission level under low-updraft (middle left) scenarios, as well as the high emission level under low-updraft (bottom left) and medium-updraft (bottom middle) scenarios. Note that low RH values do not mean that these correspond to cloud conditions. Aerosols form outside of clouds in our model, where RH can be very low. Activation will occur after aerosol formation though, when an air parcel starts rising with a given updraft velocity, in which air parcel supersaturation will develop and will cause aerosol activation.

Across all scenarios, the changes in activated number concentration between MATRIX-VBS and MATRIX range from $-56 \%$ to $+31 \%$ (Table 3 ). The range of the difference becomes more significant as emission levels increase, yet less significant as updraft velocity increases. Within most emission level-updraft velocity scenarios, as temperature increases, the fractional change in activated number concentration between the two models decreases. Also within most emission level-updraft velocity scenarios (Fig. 3, Table 4), as temperature increases, there are fewer activated particles in MATRIX. We also observed the same behavior in MATRIXVBS, higher temperature and fewer activated particles.

In order to understand the cause of the difference in activation, we traced back to the key difference between the two models: partitioning of organics. The inclusion of organics partitioning leads to changes in aerosol mixing state and size distribution, as discussed in Gao et al. (2017). Therefore, the change in activated number concentration could only be caused by changes in mass concentration, number concentra- 
Table 4. Minimum and maximum of average activated number concentration over the last $24 \mathrm{~h}$ of MATRIX and MATRIX-VBS with low-, medium-, and high-level emissions at updraft velocities of $0.5,1$, and $2 \mathrm{~m} \mathrm{~s}^{-1}$.

\begin{tabular}{llrr|rr|rr}
\hline & & \multicolumn{5}{c}{ Activated number concentration } \\
\cline { 3 - 8 } Updraft velocity $\left(\mathrm{m} \mathrm{s}^{-1}\right)$ & & \multicolumn{2}{c}{0.5} & & 1 & & 2 \\
\hline \multirow{2}{*}{ Low emission level } & MATRIX & 23 & 305 & 351 & 1160 & 963 & 2799 \\
& MATRIX-VBS & 24 & 283 & 338 & 1026 & 887 & 2473 \\
\hline Medium emission level & MATRIX & 19 & 152 & 359 & 1233 & 1476 & 3711 \\
& MATRIX-VBS & 16 & 139 & 304 & 884 & 1021 & 2498 \\
\hline High emission level & MATRIX & 3 & 60 & 199 & 1280 & 1925 & 5703 \\
& MATRIX-VBS & 3 & 63 & 185 & 1150 & 1677 & 4142 \\
\hline
\end{tabular}

(a) Number concentration by mode

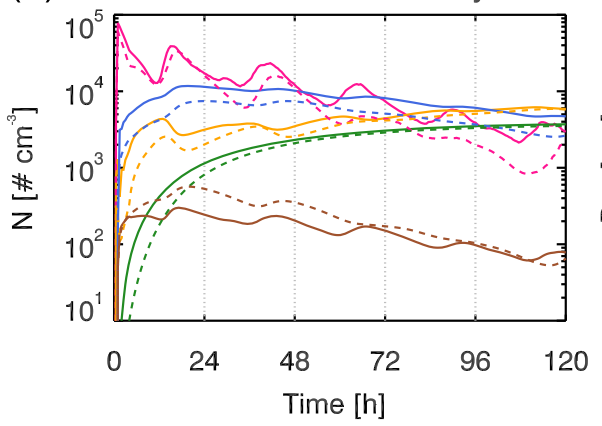

(b) Dry diameter by mode

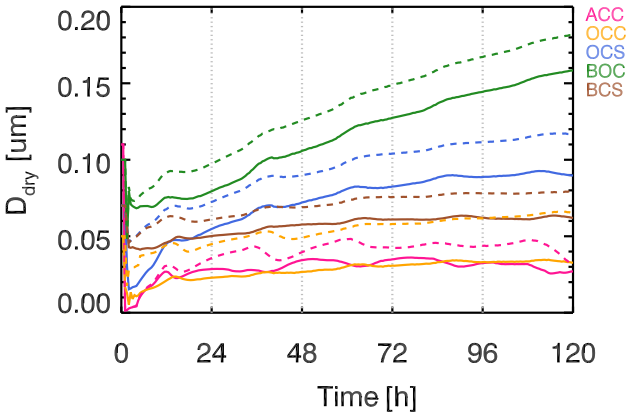

Figure 4. Number concentration (a) and dry particle diameter (b) by mode (color lines) for MATRIX (dashed lines) and MATRIX-VBS (solid lines) for the experiments with the same conditions as Fig. 1.

tion, and particle size. Since we use the Abdul-Razzak and Ghan (2000) parameterization, the activated number concentration is mainly a function of number concentration and dry particle diameter in our model. The parameterization is also a function of geometric standard deviation, which is constant per population in our model as it was in MATRIX (Bauer et al., 2008), as well as a function of aerosol composition and hygroscopicity, as mentioned in the model description, for which we assume a linear increase in solubility with decreasing volatility. The hygroscopicity of the aerosol populations changes with time, as the internal mixing of aerosol populations is altered by aerosol microphysics.

As was the case in Gao et al. (2017), MATRIX-VBS has a higher aerosol number concentration (Fig. 4 left) but smaller particles (Fig. 4 right) compared to MATRIX in the case presented in Fig. 1. At first we expected that smaller particles would be less likely to activate, so we performed a simple sensitivity test to confirm it. By changing dry particle diameter of the particles in the activation scheme, the decreasing dry particle diameter indeed led to lower activated number concentration. However, a second sensitivity test with changing only number concentration showed that higher number concentration would actually lead to lower activated number concentration as well.

In the Abdul-Razzak and Ghan (2000) scheme, increasing number concentration decreases critical supersaturation, and lower critical supersaturation leads to higher minimum dry particle radius that is able to activate. Therefore, activation is suppressed since fewer particles exceed the threshold radius. The activated number concentration is calculated from the activation fraction and the number concentration. When the fraction is greater than the increase in number concentration, lower activated number concentration is achieved, as shown here.

As mentioned previously, within most of the scenarios, there is a decrease in fractional change as temperature increases, while both models experience a decrease in activated number concentration with increased temperature. This means the decrease in activated number concentration for MATRIX-VBS is not as significant as that for MATRIX. There are two factors that contribute to such a change. First, the heat and moisture diffusion term is dependent on temperature in the activation scheme (Abdul-Razzak and Ghan, 2000). Second, volatility of organics is temperature dependent. In MATRIX-VBS, when organic volatility is consid- 
ered, the change is dampened. In other words, its number of activated particles is less sensitive to temperature change compared to MATRIX, leading to what we see in the circle plots, i.e., a greater change at lower temperatures.

The length of day and season changes the duration and intensity of gas-phase oxidation of semi-volatile gases, which is why we also looked at aerosol evolution driven by photochemistry at different latitudes. Since the model uses January emissions, different seasons are simulated in the different hemispheres, while different day lengths are simulated at higher latitudes of the Southern Hemisphere compared to Northern Hemisphere tropical and high latitudes. As we inspected results across latitudes in the two hemispheres, we found varying activated number concentration in MATRIXVBS compared to MATRIX and observed no evident trend. Such inconclusive and complex results may be due to gasphase chemistry and photochemical ageing of semi-volatile organic vapors, which would require further examination in a separate dedicated study.

\section{Conclusions}

With the inclusion of organic partitioning in an aerosol microphysics model, activated aerosol number concentration is decreased under most temperature and RH conditions, except when under low updrafts, in clean environments at most temperatures and RHs, and in polluted environments at high temperatures and extremely low-humidity conditions. Such changes are due to increased aerosol number concentration and smaller particles in the new model, as well as how number concentration and size are calculated in the chosen aerosol activation scheme, which determines how many particles are activated. Additionally, the temperature dependence of activated number concentration is decreased for most scenarios.

Our conclusion that fewer particles are activated at higher updrafts is in contrast to Connolly et al. (2014a), who found that fewer particles activated at low updrafts, using a different geometric standard deviation in the same parameterization of aerosol activation as the one we use. Such a difference can be due to the fact that the Abdul-Razzak and Ghan (2000) activation parameterization produces a different response when multiple modes are used, as shown by Connolly et al. (2014b) and Simpson et al. (2014). Additionally, in our study, the geometric standard deviation remained constant per aerosol population. However, it is worth exploring in the future to use reduced geometric standard deviation in our calculations to directly compare with values used by Connolly et al. (2014a) and Crooks et al. (2018). In fact, in a comparison study, Ghan et al. (2011) found that the AbdulRazzak and Ghan (2000) scheme tends to have lower activation fractions and droplet concentrations compared to the Fountoukis and Nenes (2005) activation scheme.
Topping et al. (2013) showed that co-condensing organics lead to enhanced cloud droplet number concentration, which seems to contradict our results. However, it is important to note that contrary to Topping et al. (2013), our study is performed in a box model that does not resolve cloud droplet growth as the air mass rises and cools, which leads to additional condensation of organic vapors and water due to the temperature decline and contributes to cloud droplet growth due to additional water uptake. The simulations in this study, however comprehensive, are still highly idealized.

We would like to emphasize that our results do not imply that the Earth has fewer $\mathrm{CCN}$ than currently thought. Instead, they imply that if in a model semi-volatile organics are simulated together with aerosol microphysics, a general decrease is to be expected, assuming our model captures all relevant contributory processes. We will investigate the effects of condensing organics in a global climate model in the future. The results presented here implicate that in the new model, most areas on Earth would experience fewer CCN on a typical day, but clean environments with above-freezing temperatures, or polluted environments on an extremely dry and hot day, would form more CCN under low-updraft-velocity conditions, compared to the old model. We expect that implementing the improved box model on the global scale that includes a two-moment cloud microphysical scheme (Morrison and Gettelman, 2008; Gettelman and Morrison, 2015) would more accurately represent aerosol-cloud interactions, which will be our focus in a follow-up study. Thus it would offer us valuable insights into how the addition of processlevel phenomena in aerosol microphysics, as applied here for the organics partitioning, would affect cloud microphysics in the global atmosphere and its implications for climate.

Data availability. The GISS ModelE Earth system model is publicly available. The box model code used here is available upon request and will be publicly available in the future as part of GISS ModelE. The data from all model simulations are available upon request.

Author contributions. The idea for this study originated from discussions among the authors, who collaboratively designed the modeling experiments. CYG developed the model, performed the experiments, and plotted all figures in the manuscript. CYG prepared the manuscript with contributions and comments from SEB and KT.

Competing interests. The authors declare that they have no conflict of interest.

Acknowledgements. We thank the NASA Earth and Space Science Fellowship Program (17-EARTH17F-85) and the NASA Modeling, Analysis, and Prediction Program for supporting Chloe Y. Gao's graduate study, as well as the NASA Atmospheric Composition 
Modeling and Analysis Program (NNX15AE36G) for supporting Susanne E. Bauer and Kostas Tsigaridis. We also thank Steven Ghan, Hyunho Lee, and Ann Fridlind for sharing their insights with us.

Edited by: Gordon McFiggans

Reviewed by: two anonymous referees

\section{References}

Abdul-Razzak, H. and Ghan, S. J.: A parameterization of aerosol activation: 2. Multiple aerosol types, J. Geophys. Res.-Atmos., 105, 6837-6844, https://doi.org/10.1029/1999JD901161, 2000.

Albrecht, B. A.: Aerosols, cloud microphysics, and fractional cloudiness, Science, 245, 1227-1230, 1989.

Anttila, T.: Sensitivity of cloud droplet formation to the numerical treatment of the particle mixing state, J. Geophys. Res., 115, D21205, https://doi.org/10.1029/2010JD013995, 2010.

Atkinson, R.: Gas-phase tropospheric chemistry of volatile organic compounds: 1. Alkanes and alkenes, J. Phys. Chem. Ref. Data, 26, 215-290, 1997.

Bauer, S. E. and Menon, S.: Aerosol direct, indirect, semidirect, and surface albedo effects from sector contributions based on the IPCC AR5 emissions for preindustrial and present-day conditions, J. Geophys. Res., 117, D01206, https://doi.org/10.1029/2011JD016816, 2012.

Bauer, S. E., Wright, D. L., Koch, D., Lewis, E. R., McGraw, R., Chang, L.-S., Schwartz, S. E., and Ruedy, R.: MATRIX (Multiconfiguration Aerosol TRacker of mIXing state): an aerosol microphysical module for global atmospheric models, Atmos. Chem. Phys., 8, 6003-6035, https://doi.org/10.5194/acp-8-60032008, 2008.

Bauer, S. E., Ault, A., and Prather, K. A.: Evaluation of aerosol mixing state classes in the GISS modelEMATRIX climate model using single-particle mass spectrometry measurements, J. Geophys. Res.-Atmos., 118, 9834-9844, https://doi.org/10.1002/jgrd.50700, 2013.

Charlson, R. J., Schwartz, S. E., Hales, J. M., Cess, R. D., Coakley, J. A., Hansen, J. E., and Hofmann, D. J.: Climate Forcing by Anthropogenic Aerosols, Science, 255, 423-430, 1992.

Connolly, P. J., Topping, D. O., Malavelle, F., and McFiggans, G.: A parameterisation for the activation of cloud drops including the effects of semi-volatile organics, Atmos. Chem. Phys., 14, 2289-2302, https://doi.org/10.5194/acp-14-2289-2014, 2014 a.

Connolly, P. J., McFiggans, G. B., Wood, R., and Tsiamis, A.: Factors determining the most efficient spray distribution for marine cloud brightening, Philos. T. R. Soc. A, 372, 20140056, https://doi.org/10.1098/rsta.2014.0056, 2014b.

Crooks, M., Connolly, P., and McFiggans, G.: A parameterisation for the co-condensation of semi-volatile organics into multiple aerosol particle modes, Geosci. Model Dev., 11, 3261-3278, https://doi.org/10.5194/gmd-11-3261-2018, 2018.

Cubison, M. J., Ervens, B., Feingold, G., Docherty, K. S., Ulbrich, I. M., Shields, L., Prather, K., Hering, S., and Jimenez, J. L.: The influence of chemical composition and mixing state of Los Angeles urban aerosol on CCN number and cloud properties, Atmos. Chem. Phys., 8, 5649-5667, https://doi.org/10.5194/acp-8-56492008, 2008.
Donahue, N. M., Robinson, A. L., Stanier, C. O., and Pandis, S. N.: Coupled partitioning, dilution, and chemical aging of semivolatile organics, Environ. Sci. Technol., 40, 2635-2643, https://doi.org/10.1021/es052297c, 2006.

Ervens, B., Cubison, M., Andrews, E., Feingold, G., Ogren, J. A., Jimenez, J. L., DeCarlo, P., and Nenes, A.: Prediction of cloud condensation nucleus number concentration using measurements of aerosol size distributions and composition and light scattering enhancement due to humidity, J. Geophys. Res., 112, D10S32, https://doi.org/10.1029/2006jd007426, 2007.

Fountoukis, C. and Nenes, A.: Continued development of a cloud droplet formation parameterization for global climate models, J. Geophys. Res., 110, D11212, https://doi.org/10.1029/2004JD005591, 2005.

Gao, C. Y., Tsigaridis, K., and Bauer, S. E.: MATRIX-VBS (v1.0): implementing an evolving organic aerosol volatility in an aerosol microphysics model, Geosci. Model Dev., 10, 751-764, https://doi.org/10.5194/gmd-10-751-2017, 2017.

Gettelman, A. and Morrison, H.: Advanced Two-Moment Bulk Microphysics for Global Models, Part I: Off-Line Tests and Comparison with Other Schemes, J. Climate, 28, 1268-1287, https://doi.org/10.1175/JCLI-D-14-00102.1, 2015.

Ghan, S. J., Guzman, G., and Abdul-Razzak, H.: Competition between sea salt and sulfate particles as cloud condensation nuclei, J. Atmos. Sci., 55, 3340-3347, 1998.

Ghan, S. J., Abdul-Razzak, H., Nenes, A., Ming, Y., Liu, X., Ovchinnikov, M., Shipway, B., Meskhidze, N., Xu, J., and Shi, $\mathrm{X}$.: Droplet nucleation: physically-based parameterizations and comparative evaluation, J. Adv. Model. Earth Sy., 3, M10001, https://doi.org/10.1029/2011MS000074, 2011.

Gibson, E. R., Gierlus, K. M., Hudson, P. K., and Grassian, V. H.: Generation of internally mixed insoluble and soluble aerosol particles to investigate the impact of atmospheric aging and heterogeneous processing on the $\mathrm{CCN}$ activity of mineral dust aerosol, Aerosol Sci. Technol., 41, 914-924, 2007.

Jimenez, J. L., Canagaratna, M. R., Donahue, N. M., Prevot, A. S. H., Zhang, Q., Kroll, J. H., DeCarlo, P. F., Allan, J. D., Coe, H., Ng, N. L., Aiken, A. C., Docherty, K. S., Ulbrich, I. M., Grieshop, A. P., Robinson, A. L., Duplissy, J., Smith, J. D., Wilson, K. R., Lanz, V. A., Hueglin, C., Sun, Y. L., Tian, J., Laaksonen, A., Raatikainen, T., Rautiainen, J., Vaattovaara, P., Ehn, M., Kulmala, M., Tomlinson, J. M., Collins, D. R., Cubison, M. J., Dunlea, E. J., Huffman, J. A., Onasch, T. B., Alfarra, M. R., Williams, P. I., Bower, K., Kondo, Y., Schneider, J., Drewnick, F., Borrmann, S., Weimer, S., Demerjian, K., Salcedo, D., Cottrell, L., Griffin, R., Takami, A., Miyoshi, T., Hatakeyama, S., Shimono, A., Sun, J. Y., Zhang, Y. M., Dzepina, K., Kimmel, J. R., Sueper, D., Jayne, J. T., Herndon, S. C., Trimborn, A. M., Williams, L. R., Wood, E. C., Middlebrook, A. M., Kolb, C. E., Baltensperger, U., and Worsnop, D. R.: Evolution of organic aerosols in the atmosphere, Science, 326, 1525-1529, https://doi.org/10.1126/science.1180353, 2009.

McFiggans, G., Artaxo, P., Baltensperger, U., Coe, H., Facchini, M. C., Feingold, G., Fuzzi, S., Gysel, M., Laaksonen, A., Lohmann, U., Mentel, T. F., Murphy, D. M., O’Dowd, C. D., Snider, J. R., and Weingartner, E.: The effect of physical and chemical aerosol properties on warm cloud droplet activation, Atmos. Chem. Phys., 6, 2593-2649, https://doi.org/10.5194/acp-6-25932006, 2006. 
Medina, J., Nenes, A., Sotiropoulou, R.-E. P., Cottrell, L. D., Ziemba, L. D., Beckman, P. J., and Griffin, R. J.: Cloud condensation nuclei closure during the International Consortium for Atmospheric Research on Transport and Transformation 2004 campaign: Effects of size-resolved composition, J. Geophys. Res., 112, D10S31, https://doi.org/10.1029/2006jd007588, 2007.

Ming, Y., Ramaswamy, V., Donner, L. J., and Phillips, V. T. J.: A new parameterization of cloud droplet activation applicable to general circulation models, J. Atmos. Sci., 63, 1348-1356, 2006.

Morrison, H. and Gettelman, A.: A new two-moment bulk stratiform cloud microphysics scheme in the Community Atmosphere Model, version 3 (CAM3). Part I: Description and numerical tests, J. Climate, 21, 3642-3659, https://doi.org/10.1175/2008JCLI2105.1, 2008.

Myhre, G., Shindell, D., Bréon, F.-M., Collins, W., Fuglestvedt, J., Huang, J., Koch, D., Lamarque, J.-F., Lee, D., Mendoza, B., Nakajima, T., Robock, A., Stephens, G., Takemura T., and Zhang, H.: Anthropogenic and Natural Radiative Forcing, in: Climate Change 2013: The Physical Science Basis. Contribution of Working Group I to the Fifth Assessment Report of the Intergovernmental Panel on Climate Change, edited by: Stocker, T. F., Qin, D., Plattner, G.-K., Tignor, M., Allen, S. K., Boschung, J., Nauels, A., Xia, Y., Bex, V., and Midgley, P. M., Cambridge University Press, Cambridge, UK and New York, NY, USA, 659740, https://doi.org/10.1017/CBO9781107415324, 2013.

Pankow, J. F.: An absorption model of gas/particle partitioning of organic compounds in the atmosphere, Atmos. Environ., 28, 185-188, 1994.

Petters, M. D. and Kreidenweis, S. M.: A single parameter representation of hygroscopic growth and cloud condensation nucleus activity, Atmos. Chem. Phys., 7, 1961-1971, https://doi.org/10.5194/acp-7-1961-2007, 2007.

Petters, M. D., Prenni, A. J., Kreidenweis, S. M., DeMott, P. J., Matsunaga, A., Lim, Y. B., and Ziemann, P. J.: Chemical aging and the hydrophobic-hydrophilic conversion of carbonaceous aerosol, Geophys. Res. Lett., 33, L24806, https://doi.org/10.1029/2006GL027249, 2006.

Pierce, J. R., Riipinen, I., Kulmala, M., Ehn, M., Petäjä, T., Junninen, H., Worsnop, D. R., and Donahue, N. M.: Quantification of the volatility of secondary organic compounds in ultrafine particles during nucleation events, Atmos. Chem. Phys., 11, 90199036, https://doi.org/10.5194/acp-11-9019-2011, 2011.

Rastak, N., Pajunoja, A., Navarro, J. C. A., Ma, J., Song, M., Partridge, D. G., Kirkevag, A., Leong, Y., Hu, W. W., Taylor, N. F., Lambe, A., Cerully, K., Bougiatioti, A., Liu, P., Krejci, R., Petaja, T., Percival, C., Davidovits, P., Worsnop, D. R., Ekman, A. M. L., Nenes, A., Martin, S., Jimenez, J. L., Collins, D. R., Topping, D. O., Bertram, A. K., Zuend, A., Virtanen, A., and Riipinen, I.: Microphysical explanation of the $\mathrm{RH}$-dependent water affinity of biogenic organic aerosol and its importance for climate, Geophys. Res. Lett., 44, 5167-5177, https://doi.org/10.1002/2017gl073056, 2017.

Reutter, P., Su, H., Trentmann, J., Simmel, M., Rose, D., Gunthe, S. S., Wernli, H., Andreae, M. O., and Pöschl, U.: Aerosol- and updraft-limited regimes of cloud droplet formation: influence of particle number, size and hygroscopicity on the activation of cloud condensation nuclei (CCN), Atmos. Chem. Phys., 9, 70677080, https://doi.org/10.5194/acp-9-7067-2009, 2009.
Riipinen, I., Pierce, J. R., Yli-Juuti, T., Nieminen, T., Häkkinen, S., Ehn, M., Junninen, H., Lehtipalo, K., Petäjä, T., Slowik, J., Chang, R., Shantz, N. C., Abbatt, J., Leaitch, W. R., Kerminen, V.-M., Worsnop, D. R., Pandis, S. N., Donahue, N. M., and Kulmala, M.: Organic condensation: a vital link connecting aerosol formation to cloud condensation nuclei (CCN) concentrations, Atmos. Chem. Phys., 11, 3865-3878, https://doi.org/10.5194/acp-11-3865-2011, 2011.

Schmidt, G. A., Kelley, M., Nazarenko, L., Ruedy, R., Russell, G. L., Aleinov, I., Bauer, M., Bauer, S. E., Bhat, M. K., Bleck, R., Canuto, V., Chen, Y., Cheng, Y., Clune, T. L., Del Genio, A., de Fainchtein, R., Faluvegi, G., Hansen, J. E., Healy, R. J., Kiang, N. Y., Koch, D., Lacis, A. A., LeGrande, A. N., Lerner, J., Lo, K. K., Matthews, E. E., Menon, S., Miller, R. L., Oinas, V., Oloso, A. O., Perlwitz, J. P., Puma, M. J., Putman, W. M., Rind, D., Romanou, A., Sato, M., Shindell, D. T., Sun, S., Syed, R. A., Tausnev, N., Tsigaridis, K., Unger, N., Voulgarakis, A., Yao, M.-S., and Zhang, J.: Configuration and assessment of the GISS ModelE2 contributions to the CMIP5 archive, J. Adv. Model. Earth Sy., 6, 141-184, https://doi.org/10.1002/2013MS000265, 2014.

Scott, C. E., Spracklen, D. V., Pierce, J. R., Riipinen, I., D'Andrea, S. D., Rap, A., Carslaw, K. S., Forster, P. M., Artaxo, P., Kulmala, M., Rizzo, L. V., Swietlicki, E., Mann, G. W., and Pringle, K. J.: Impact of gas-to-particle partitioning approaches on the simulated radiative effects of biogenic secondary organic aerosol, Atmos. Chem. Phys., 15, 12989-13001, https://doi.org/10.5194/acp-15-12989-2015, 2015.

Seinfeld, J. H. and Pandis, S. N.: Atmospheric Chemistry and Physics: From Air Pollution to Climate Change, 3rd Edn., John Wiley \& Sons Inc., Hoboken, New Jersey, 2016.

Shipway, B. J. and Abel, S. J.: Analytical estimation of cloud droplet nucleation based on an underlying aerosol population, Atmos. Res., 96, 344-355, 2010.

Simpson, E., Connolly, P., and McFiggans, G.: An investigation into the performance of four cloud droplet activation parameterisations, Geosci. Model Dev., 7, 1535-1542, https://doi.org/10.5194/gmd-7-1535-2014, 2014.

Storelvmo, T., Kristjánsson, J. E., Ghan, S. J., Kirkevåg, A., Seland, $\varnothing$., and Iversen, T.: Predicting cloud droplet number concentration in Community Atmosphere Model (CAM)-Oslo, J. Geophys. Res., 111, D24208, https://doi.org/10.1029/2005JD006300, 2006.

Topping, D., Connolly, P., and McFiggans, G.: Cloud droplet number enhanced by co-condensation of organic vapours, Nat. Geosci., 6, 443-446, 2013.

Twomey, S. A.: Pollution and the Planetary albedo, Atmos. Environ., 8, 1251-1256, 1974.

Yu, F.: A secondary organic aerosol formation model considering successive oxidation aging and kinetic condensation of organic compounds: global scale implications, Atmos. Chem. Phys., 11, 1083-1099, https://doi.org/10.5194/acp-11-1083-2011, 2011. 